\title{
Fabrication of Carbon Nanofibers Decorated with Various Kinds of Metal Oxides for Battery Applications
}

\author{
Jung-Pil Lee ${ }^{1,+}{ }^{\mathbb{D}}$, Sinho Choi ${ }^{2,+}$, Sungjin Cho $^{3}$, Woo-Jin Song ${ }^{4, *}$ and Soojin Park ${ }^{3, *}$ \\ 1 Interdisciplinary School of Green Energy, Ulsan National Institute of Science and Technology (UNIST), \\ Ulsan 689-798, Korea; jplee0711@naver.com \\ 2 Korea Institute of Energy Research, Ulsan Advanced Energy Technology R\&D Center, Ulsan 44776, Korea; \\ schoi@kier.re.kr \\ 3 Department of Chemistry, Pohang University of Science and Technology (POSTECH), Pohang 37673, Korea; \\ tjdwls820@postech.ac.kr \\ 4 Department of Organic Materials Engineering, Chungnam National University, Daejeon 34134, Korea \\ * Correspondence: wjsong@cnu.ac.kr (W.-J.S.); soojin.park@postech.ac.kr (S.P.) \\ + J.-P.L. and S.C. contributed equally to this work.
}

check for updates

Citation: Lee, J.-P.; Choi, S.; Cho, S.; Song, W.-J.; Park, S. Fabrication of Carbon Nanofibers Decorated with Various Kinds of Metal Oxides for Battery Applications. Energies 2021, 14, 1353. https://doi.org/10.3390/ en14051353

Academic Editor: Yeonguk Son

Received: 4 January 2021

Accepted: 22 February 2021

Published: 2 March 2021

Publisher's Note: MDPI stays neutral with regard to jurisdictional claims in published maps and institutional affiliations.

Copyright: (c) 2021 by the authors. Licensee MDPI, Basel, Switzerland. This article is an open access article distributed under the terms and conditions of the Creative Commons Attribution (CC BY) license (https:// creativecommons.org/licenses/by/ $4.0 /)$.

\begin{abstract}
Carbon nanofibers decorated with various metal oxide nanoparticles were fabricated by combining an electrospinning technique of bicomponent polymer mixture and a sol-gel reaction and subsequent carbonization process. Electrospun polymer nanofibers consisting of polyacrylonitrile (PAN) and poly(vinyl pyrrolidone) (PVP) with controllable diameters were fabricated with PAN/PVP core/shell types via phase-separation due to the immiscibility between two polymers. The electrospun nanofibers served as supporting materials with binding sites of PVP to incorporate titanium oxide precursor. Subsequently, the carbonization of the fibers led to the formation of carbon nanofibers@ $\mathrm{TiO}_{2}$ for energy application, in which rutile $\mathrm{TiO}_{2}$ nanoparticles were decorated on the surface of carbon nanofiber. Especially, this $\mathrm{TiO}_{2}$ decorated carbon nanofiber electrode exhibited excellent electrochemical property in lithium-ion batteries $\left(\approx 600 \mathrm{~mA} \mathrm{~h} \mathrm{~g}^{-1}\right.$ at $\mathrm{C} / 5$ rate for 100 cycles). Furthermore, the carbon nanofibers were also successfully modified with other metal oxides, including $\mathrm{NiO}, \mathrm{SnO}_{2}$, and $\mathrm{ZrO}_{2}$ nanoparticles, in a similar manner.
\end{abstract}

Keywords: carbon nanofibers; electrospinning; metal oxides; alkoxides; composites; Li-ion batteries

\section{Introduction}

Carbon-based nanomaterials with different dimensions (e.g., fullerenes, carbon nanotubes, carbon nanofibers, graphene, and porous structures) have attracted significant interest due to their outstanding physical and chemical properties [1-9]. Among them, carbon nanofibers, particularly, have the unique features of high electrical conductivity, electrochemical stability, and high specific surface area [10-14]. Moreover, carbon nanofibers can be produced readily and cost-effectively in a large scale [15]. Utilizing carbon nanofibers as a conductive support has various advantages for potential applications in electronics, sensors, and electrochemical energy devices [16-20]. Nevertheless, substantial efforts have been made to evaluate their performance since pristine carbon nanofibers show limited performance in typical applications.

Surface modification of carbon nanofibers with metal oxides has been considered as an efficient route for these purposes by combining the advantages of both components [21,22]. Metal oxides have received significant attention due to their high thermal and chemical stability, availability of green chemistry synthetic route, and diverse technical applications [23-25]. For example, $\mathrm{TiO}_{2}$ is one of the most appropriate candidates for photocatalytic processes owing to its powerful oxidation capability, superior charge transport, and corrosion resistance [26-29]. Desirable photocatalytic properties, including enhanced absorption in the visible region, electron conductivity, and stability, were obtained by 
incorporating carbon nanostructures with $\mathrm{TiO}_{2}[30,31]$. Moreover, many research groups have also reported remarkable enhancement of strength, thermal, and chemical stability of metal oxide-embedded carbon nanofibers [32-34].

Up to now, to prepare composite materials with one-dimensional structures, various synthetic routes have been developed, including electrospinning, self-assembly, nanolithography, and templating techniques [35-37]. Among them, electrospinning has been widely employed due to its simple but straightforward process for synthesizing nanofibers with tailored morphologies and controllable diameters ranging from nano- to micrometerscale [38-40]. This technique allows us an opportunity to fabricate a free-standing electrode with high mechanical and electrochemical performance for flexible lithium-ion batteries [41,42]. Additionally, to fulfill and ameliorate the energy density of the flexible batteries, metal oxide is thought to be a promising candidate as an active material due to several advantages, such as eco-friendly material and cost-effective features [43]. In composite nanofibers generated by electrospinning, however, the additives are normally encapsulated inside the polymer matrix, which can reduce the reactivity and response [44]. Furthermore, since the loading amount of one component in the composite can affect the viscosity of polymer solutions, there are some limitations when generating electrospun fibers with controlled morphologies.

Herein, we propose a novel method for fabricating various metal oxides, such as $\mathrm{TiO}_{2}, \mathrm{NiO}, \mathrm{SnO}_{2}$, and $\mathrm{ZrO}_{2}$, on the surface of carbon nanofibers produced by combining electrospinning and sol-gel techniques. Uniform polyacrylonitrile (PAN)/poly(vinyl pyrrolidone) (PVP) electrospun fibers with controlled diameters were generated by manipulating polymer viscosity. The metal oxide nanoparticles were formed on the surface of carbon nanofibers by immersing electrospun polymer nanofibers into the metal alkoxide solution and subsequently carbonizing to convert the alkoxide to metal oxide. Moreover, high contents of metal oxides were successfully loaded on the surface of carbon nanofibers by simply tuning the concentration of alkoxide solutions.

\section{Materials and Methods}

Materials: Polyacrylonitrile (PAN, Mw $=150 \mathrm{~kg} / \mathrm{mol}$ ) and poly (vinyl pyrrolidone) (PVP, Mw $=1300 \mathrm{~kg} / \mathrm{mol}$ ) were purchased from Sigma-Aldrich (Seoul, Republic of Korea). N,N'-dimethylformamide (DMF, anhydrous, 99.8\%) was obtained from Sigma-Aldrich. Titanium (IV) butoxide (97\%, Sigma-Aldrich), nickel (II) 2-ethylhexanoate monoisopropoxide (99\%, 5\% $w / v$ in isopropanol, Alfa-Aesar), tin (IV) isopropoxide (99\% (metals basis), 10\% $w / v$ in isopropanol, Alfa-Aesar), and zirconium (IV) butoxide solution (80\%, Sigma-Aldrich) were used as sol-gel precursors. Hexane (95\%) was obtained from Sigma-Aldrich. All chemicals were used as received without further purification.

Preparation of carbon nanofibers decorated with various metal oxides: Before electrospinning, blends of PAN and PVP were prepared by dissolving PAN and PVP (concentrations of 10,15 , and $20 \mathrm{wt} \%$ ) in $\mathrm{DMF}$ at a mass ratio of $1: 1$ at $80{ }^{\circ} \mathrm{C}$ under magnetic stirring for $24 \mathrm{~h}$ to obtain a homogeneous solution. The resulting polymer solutions were transferred into a plastic syringe equipped for the electrospinning process. A variable high voltage power supply (Gamma High Voltage Research, ES40P-20W) was used to provide desired voltage (15-20 kV) depending on the concentration of the PAN/PVP solution for electrospinning. The needle tip was connected to the positive terminal of the high voltage power supply, and grounded aluminum (Al) foil was used as a target collector. The feeding rate of the polymer solution and distance between tip and collector were $1.2 \mathrm{~mL} / \mathrm{h}$ and $15 \mathrm{~cm}$, respectively. Electrospun polymer nanofibers were collected on the Al foil and dried in a vacuum to remove residual solvent. Then, the PAN/PVP nanofiber sheets were detached from the $\mathrm{Al}$ foil and immersed into alkoxide solutions diluted in hexane $(0.1-0.5 \mathrm{~mL} / \mathrm{mL}$ ) for $1 \mathrm{~h}$. Alkoxides-loaded PAN/PVP sheets were washed with excess hexane and dried in a vacuum oven for $24 \mathrm{~h}$. The PAN/PVP nanofiber sheets with alkoxides were placed into a tube furnace for heat treatment. The samples were heated at a rate of $1{ }^{\circ} \mathrm{C} / \mathrm{min}$ to $280^{\circ} \mathrm{C}$ in the air to make $\mathrm{TiO}_{2}$ nanoparticles, held for $1 \mathrm{~h}$ to stabilize the 
electrospun fibers, and carbonized at $800{ }^{\circ} \mathrm{C}$ for $1 \mathrm{~h}$ under a flowing nitrogen/hydrogen $(95 \% / 5 \%)$ mixture gas. The gas flow rate was adjusted to keep the net flow rate at $5 \mathrm{sccm}$.

Electrochemical test of Carbon nanofiber@ $\mathrm{TiO}_{2}$ electrode: A freestanding carbon nanofiber@ $\mathrm{TiO}_{2}$ electrode was made from PAN/PVP nanofiber sheets by electrospinning and heat treatment. The mass loading of the electrode was $1 \mathrm{mg} \mathrm{cm}^{-2}$. Electrochemical properties of the half cell were evaluated using coin-type half-cells (2016R) that were composed of active materials (the freestanding carbon nanofiber@ $\mathrm{TiO}_{2}$ composite electrodes) as the working electrode and lithium metal as a counter electrode, which were prepared under an argon-filled glove box. The electrolyte was 1.3 M LiPF6 with ethylene carbonate/diethyl carbonate (PANAX Starlyte, Korea, $3 / 7(v / v)$ ) including $10 \mathrm{wt} \%$ fluoroethylene carbonate additive. The half-cells were tested galvanostatically between 0.01 and $3.0 \mathrm{~V}$ (versus $\mathrm{Li} / \mathrm{Li}+$ ) at C/20 and C/5 rates using WBCS 3000 battery systems.

Characterization: Surface morphologies of polymer fibers, alkoxide-loaded sample, and metal oxide-decorated carbon nanofibers were investigated by a scanning electron microscope (SEM Leo/Zeiss 1530). For the Transmission electron microscopy (TEM) characterization, the products were transferred onto a copper grid after dispersion by sonication in ethanol, and a JEM-1400 was used to obtain TEM images at an accelerating voltage of $100 \mathrm{kV}$. The crystalline phases of the samples were identified using X-ray diffraction (XRD) analysis (PANalytical X'Pert PRO Alpha-1 with Cu K- $\alpha 1$ source). Raman spectra were obtained using a Renishaw RM 1000 spectromicroscopy system ( $\approx 2 \mu \mathrm{m}$ spot size). $\mathrm{He}-\mathrm{Ne}$ laser emission at wavelengths of $633 \mathrm{~nm}$ was used for excitation in this study. The thermogravimetric analysis (TA Instruments SDT-Q600) was used to determine the weight of the metal oxides loaded to carbon nanofibers with a heating rate of $10^{\circ} \mathrm{C} / \mathrm{min}$ under air condition.

\section{Results}

Schematic illustration shows the overall procedure composed of three steps for fabricating carbon nanofibers decorated with metal oxides (Figure 1). The electrospun nanofibers of PAN/PVP mixtures were collected on the Al foil in the first step. The PAN and PVP were phase-separated upon electrospinning process due to the incompatibility between PAN and PVP. Subsequently, numerous alkoxides, as a precursor of metal oxide, were coated on the surface of electrospun PAN/PVP bicomponent fiber sheets. In the final step, carbon nanofibers decorated with many kinds of metal oxides were generated by carbonization of the polymer fibers and calcination of alkoxides to metal oxides.

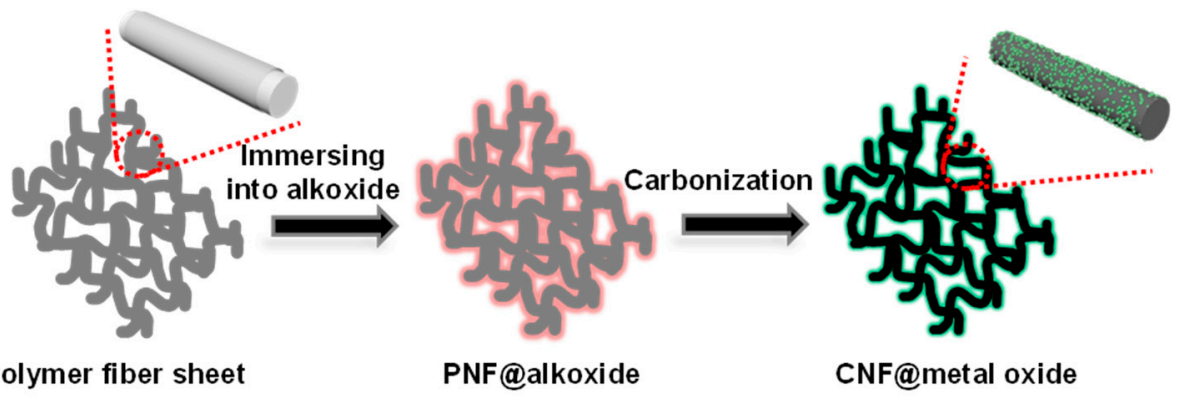

Figure 1. Scheme of the fabrication of carbon nanofibers decorated with various metal oxide nanoparticles.

PAN and PVP were chosen to serve as carbon sources and binding moieties of metal oxide precursors in the phase-separated PAN/PVP blend systems, respectively. Figure 2a shows a typical SEM image of the electrospun PAN/PVP nanofibers. As observed in Figure 2a, the bicomponent nanofibers were successfully generated without formation of any droplets (or beads). Electrospun PAN/PVP nanofibers have smooth surfaces with an average diameter of $\approx 297 \mathrm{~nm}$. It is well-known that the bicomponent nanofibers of PAN and PVP form phase-separated structures in the blended system due to their 
immiscibility [45]. To confirm the structures of bicomponent polymer fibers, the electrospun fibers were hydrothermally treated in an autoclave at $90^{\circ} \mathrm{C}$, since PVP dissolves well in water while PAN is insoluble. Figure $2 b$ shows the SEM image of polymer nanofibers produced after water treatment. The average diameter of water-extracted nanofibers is $\approx 246 \mathrm{~nm}$, which is smaller than that of the as-electrospun fibers. It means that PVP parts were selectively dissolved out from bicomponent nanofibers.

Thermoplastic PAN fibers were converted to thermosetting plastics via laddering of their binding during the stabilization step in the oxidative atmosphere [46]. The asprepared carbon nanofibers have a smaller diameter than the polymer nanofibers due to the pyrolysis of organic species and carbon densification during the heating process. It was seen that the carbon nanofibers have very smooth surface morphologies (Figure 2c).
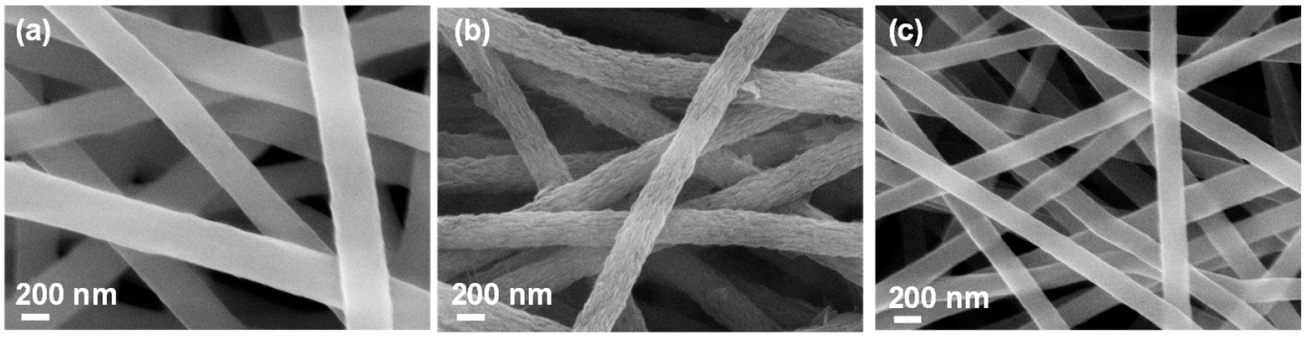

Figure 2. SEM images of polyacrylonitrile (PAN)/poly(vinyl pyrrolidone) (PVP) bicomponent nanofibers (a) before and (b) after water extraction, and (c) pyrolyzed carbon nanofibers.

PVP can provide the binding sites of inorganic materials, while PAN serves as one of the best precursors of carbon. Because PVP portions were the outer shell of the bicomponent nanofibers, Ti precursors can be readily combined with the PVP portion through a coordinated covalent bond with the partial negative charge of oxygen in the PVP structure [41]. Thus, titanium butoxide, a widely used $\mathrm{TiO}_{2}$ precursor in sol-gel reactions, was incorporated into the as-prepared PAN/PVP nanofibers by immersing nanofiber sheets into the precursor solution. The bicomponent nanofibers decorated with Ti precursors were converted to carbon nanofibers@ $\mathrm{TiO}_{2}\left(\mathrm{CNF} @ \mathrm{TiO}_{2}\right)$ after a one-step heat treatment. Figure 3a shows that $\mathrm{TiO}_{2}$ nanoparticles with a diameter of $10 \mathrm{~nm}$ were coated on the surface of the carbon nanofibers. For the clear view of the composition of the $\mathrm{CNF} @ \mathrm{TiO}_{2}$, the samples were characterized by TEM and energy dispersive X-ray spectroscopy (EDX) line profiles. $\mathrm{TiO}_{2}$ nanoparticles were positioned on the surface of the carbon nanofibers, not encapsulated in the carbon nanofibers, as shown Figure 3.

Generally, 1-D structures using solution mixtures of polymer and different species to introduce certain chemical or physical properties were produced by electrospinning. The additives were embedded into a polymer or carbon fiber matrix in the hybrid polymer or carbon nanofibers due to the nature of the electrospinning method. In this case, the matrix layer can prevent the contact between additives and other materials or atmospheres, resulting in a reduction in reactivity or performance. Meanwhile, carbon nanofibers decorated with $\mathrm{TiO}_{2}$ nanoparticles can exhibit their properties, since the $\mathrm{TiO}_{2}$ nanoparticles are exposed to the exterior environment.

Figure 4a displays XRD patterns of the electrospun PAN/PVP nanofibers immersed into the solution of Ti butoxides before and after the carbonization process to demonstrate the degree of transformation of $\mathrm{Ti}$ precursor to $\mathrm{TiO}_{2}$. There are no obvious diffraction peaks in the samples before the heat-treatment because the structure of $\mathrm{TiO}_{2}$ as-synthesized from hydrolyzing the alkoxide is amorphous [47]. However, the XRD patterns of the $\mathrm{CNF} @ \mathrm{TiO}_{2}$ produced after carbonization at $800{ }^{\circ} \mathrm{C}$ show the typical diffraction peaks for crystalline $\mathrm{TiO}_{2}$. The characteristic diffraction peaks of $\mathrm{TiO}_{2}$ can be found at several positions, indicating the complete reduction to form crystalline $\mathrm{TiO}_{2}$ during the one-step carbonization. It was found that the crystalline phases of the $\mathrm{TiO}_{2}$ nanoparticles on the 
carbon nanofibers observed using XRD were composed primarily of rutile in structure with a minority phase of anatase (JCPDS file No.84-1285 and 74-1219).
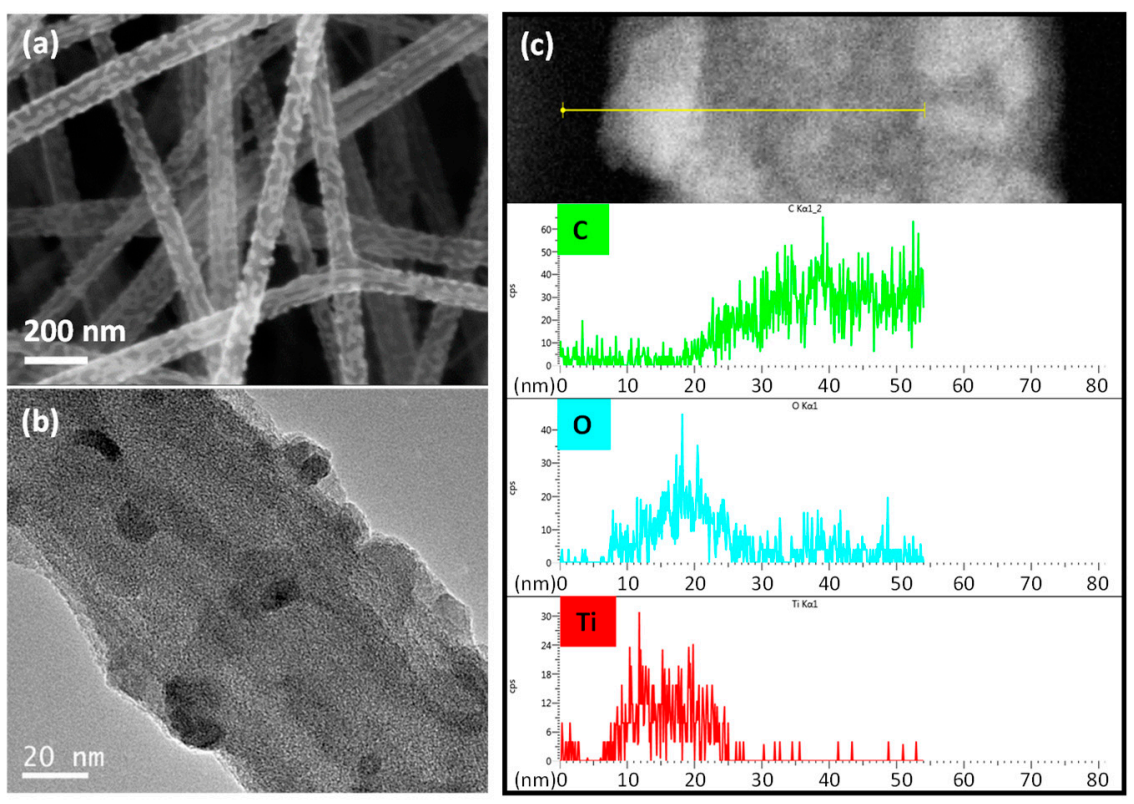

Figure 3. Morphologies of carbon nanofibers with $\mathrm{TiO}_{2}$ (a) SEM image and (b) TEM image of carbon nanofibers decorated with $\mathrm{TiO}_{2}$ nanoparticles $(10 \mathrm{wt} \% \mathrm{PAN} / \mathrm{PVP}$ with $0.1 \mathrm{~mL} / \mathrm{mL} \mathrm{TiO}$ precursor solution). (c) EDS line-scan profiles showing spatial locations of $\mathrm{C}, \mathrm{O}$, and Ti.

(a) XRD pattern

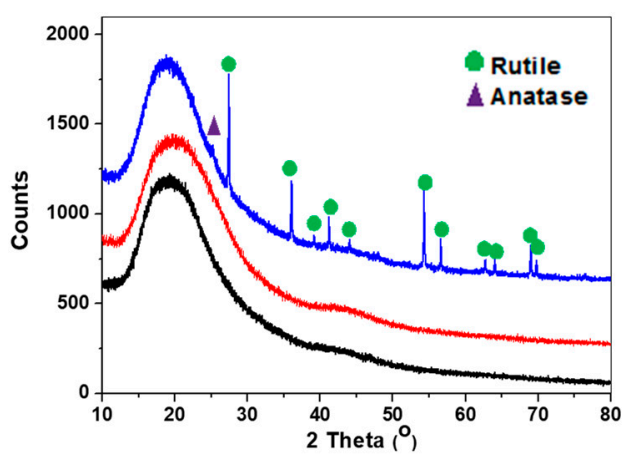

(b) Raman spectra

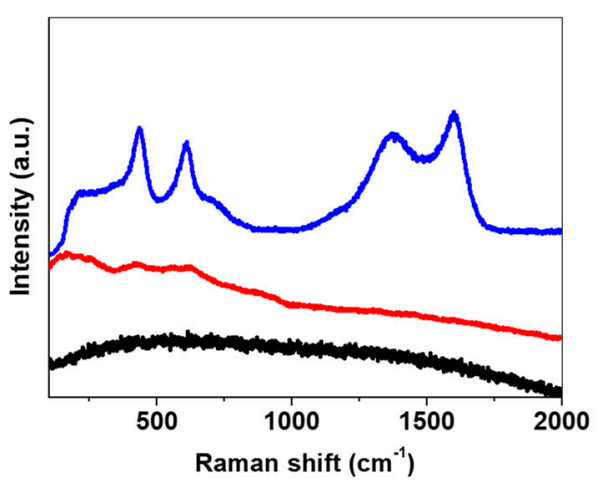

Figure 4. Characterization of nanofibers fabricated by each step. (a) XRD patterns and (b) Raman spectra of PAN/PVP (Black), PAN/PVP@TiBu (Red), and $\mathrm{TiO}_{2}$ decorated carbon nanofiber (Blue).

The Raman spectra of the samples before and after the carbonization process are shown in Figure $4 \mathrm{~b}$. The production of carbon was confirmed after the carbonization step of PAN, while there are no typical peaks in the case of non-carbonized PAN. The fundamental vibrations of the carbon after carbonization were observed at $1600 \mathrm{~cm}^{-1}$ and $1370 \mathrm{~cm}^{-1}$, corresponding to the graphite band (G-band) and the disorder band (D-band), respectively. The intensity ratio of $\mathrm{D}$ band to $\mathrm{G}$ band (ID/IG) of the sample were calculated to be about 1.15 , indicating amorphous characteristics of carbon [48]. The characteristic bands of $\mathrm{TiO}_{2}$ detected at 436 and $612 \mathrm{~cm}^{-1}$, which correspond to the rutile modes [42], indicate the conversion of $\mathrm{Ti}$ precursors to $\mathrm{TiO}_{2}$, which is consistent with the XRD result. It should be noted that this preparation route is suitable for generating high-quality $\mathrm{CNF}_{\mathrm{T}} \mathrm{TiO}_{2}$.

Figure 5 shows the $\mathrm{TiO}_{2}$ coated carbon nanofibers with different diameters. The diameters of the electrospun nanofibers were influenced by the viscosity of the polymer solutions, which were controlled by varying the concentrations of the PAN/PVP. When 
the concentration of PAN/PVP solution was increased from $10 \mathrm{wt} \%$ to 15 and $20 \mathrm{wt} \%$, the diameter of the carbon nanofibers was increased from $80 \mathrm{~nm}$ to $200 \mathrm{~nm}$ and $450 \mathrm{~nm}$, respectively. Furthermore, the population of $\mathrm{TiO}_{2}$ on the carbon nanofibers was also controlled by manipulating the amount of Ti precursors. At higher concentrations of $\mathrm{Ti}$ butoxide solution (Figure 5c), larger amounts of Ti precursors were deposited and grown on the PVP. After carbonization, the oxide mass loading correspondingly increased, as shown in Figure 3.
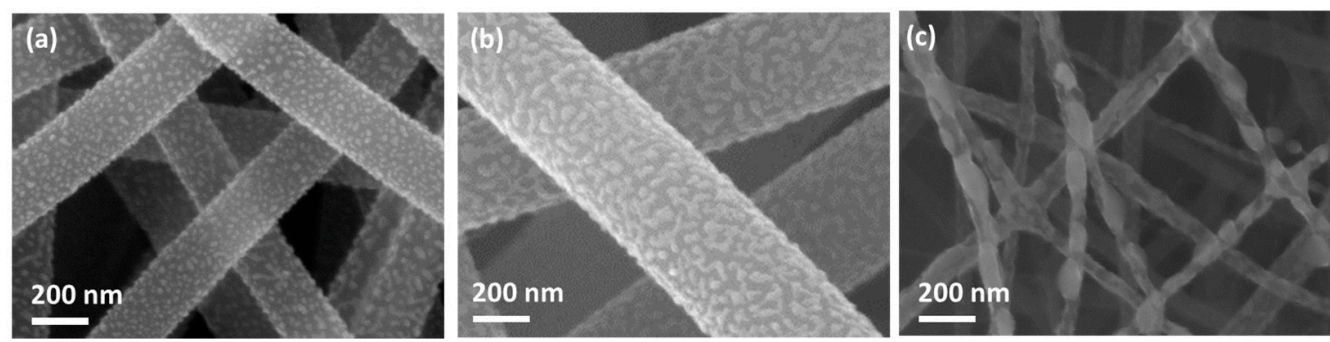

Figure 5. SEM images of $\mathrm{CNF} @ \mathrm{TiO}_{2}$ with different diameters and quantities produced with the following conditions: (a) $15 \mathrm{wt} \% \mathrm{PAN} / \mathrm{PVP}$ with $0.1 \mathrm{~mL} / \mathrm{mL} \mathrm{TiO} 2$ precursor solution, (b) $20 \mathrm{wt} \%$ $\mathrm{PAN} / \mathrm{PVP}$ with $0.1 \mathrm{~mL} / \mathrm{mL} \mathrm{TiO}_{2}$ precursor solution, and (c) $10 \mathrm{wt} \% \mathrm{PAN} / \mathrm{PVP}$ with $0.5 \mathrm{~mL} / \mathrm{mL}$ $\mathrm{TiO}_{2}$ precursor solution.

The amount of $\mathrm{TiO}_{2}$ on the surface of the electrospun carbon nanofibers was quantified by TGA. Figure 6 shows the TGA curves of the samples with different diameters of carbon nanofibers and amounts of $\mathrm{TiO}_{2}$. The major weight loss region was associated with the combustion of the carbon nanofibers, where the carbon began degrading at $450{ }^{\circ} \mathrm{C}$ and was completely burned out. The weight percentage of remaining $\mathrm{TiO}_{2}$ on the carbon nanofibers prepared using PAN/PVP ( $20 \mathrm{wt} \%$ ) was calculated to $\approx 5 \mathrm{wt} \%$. An increase of metal oxide amount is necessary to evaluate the energy density, particularly for energyrelated applications such as lithium-ion batteries and supercapacitors. From this point of view, samples with a higher mass loading of $\mathrm{TiO}_{2}$ were obtained by decreasing the amount of carbon sources. As a result, the mass of $\mathrm{TiO}_{2}$ was increased up to $65 \mathrm{wt} \%$ in the samples with the smallest diameter and the highest loading concentration of $\mathrm{TiO}_{2}$ precursor solution, as shown in Figure 6. Therefore, carbon nanofibers decorated with a high mass loading of $\mathrm{TiO}_{2}$ by our approach may be candidate materials to exhibit high performance in energy application.

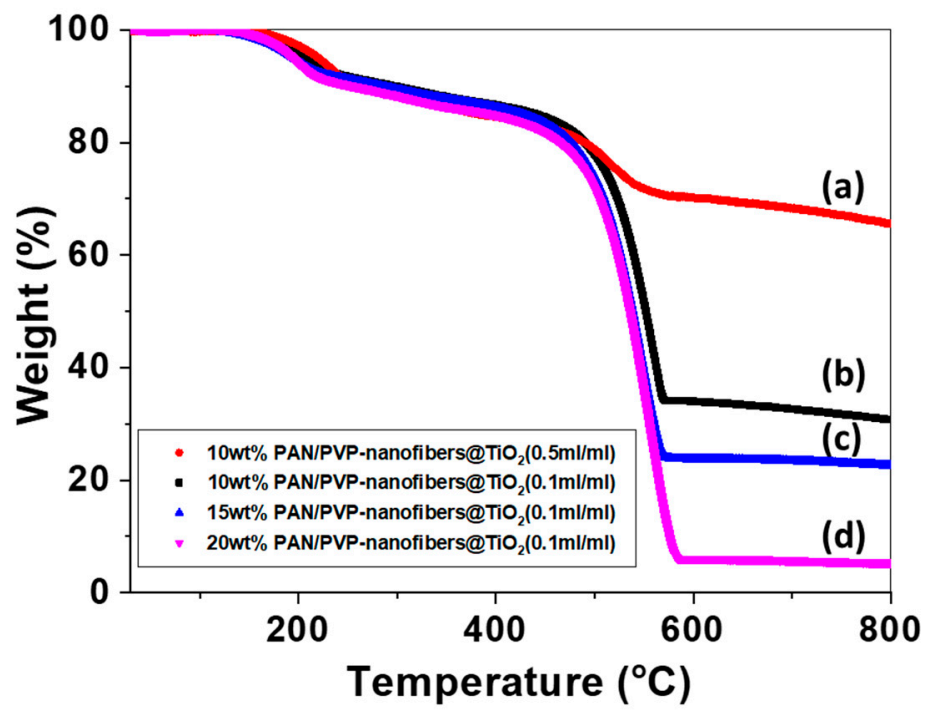

Figure 6. TGA profiles of $\mathrm{CNF} @ \mathrm{TiO}_{2}$ with different $\mathrm{TiO}_{2}$ quantities of (a) 65\% (Red), (b) 30\% (Black), (c) $20 \%$ (Blue), and (d) $5 \%$ (Magenta). 
Several $\mathrm{TiO}_{2}$ decorated carbon nanofiber composites were tested as anode materials in lithium-ion batteries. Figure 7 a shows the freestanding electrode with different amounts of $\mathrm{TiO}_{2}$, which was flexible and did not have any physical damage under bending conditions. However, another electrode with large amounts of $\mathrm{TiO}_{2}(65 \mathrm{wt} \%)$ shows many cracks and breakdown of the electrode as it was brittle due to low carbon content in its nanofibers. In the first cycle voltage and differential capacity $(\mathrm{dQ} / \mathrm{dV})$ profiles of the discharging (lithiation) and charging (delithiation) of the $\mathrm{CNF} @ \mathrm{TiO}_{2}$ composite electrodes with different amounts of $\mathrm{TiO}_{2}$ at a rate of $\mathrm{C} / 20$ in the range of 0.01-3.0 V, the first discharge capacities of $\mathrm{CNF} @ \mathrm{TiO}_{2}\left(20 \mathrm{wt} \% \mathrm{TiO}_{2}\right.$ and $\left.30 \mathrm{wt} \% \mathrm{TiO}_{2}\right)$ were 1755 and $1605 \mathrm{~mA} \mathrm{~h} \mathrm{~g}{ }^{-1}$, respectively (Supplementary Material, Figure S1). To further demonstrate the stability of the electrode during the electrochemical analysis, cyclic voltammetry (CV) and SEM analysis were conducted (Supplementary Material, Figure S2). The results indicated that the proposed electrode was stable. Increasing $\mathrm{TiO}_{2}$ contents in the composite electrodes led to decreasing gravimetric capacity due to little specific capacity of $\mathrm{TiO}_{2}$ compared to CNFs. However, the cycling performances of all of the $\mathrm{CNF@} \mathrm{TiO}_{2}$ composite anodes exhibit a highly stable property (Figure $7 \mathrm{~b}, \mathrm{c}$ ). The $20 \mathrm{wt} \% \mathrm{TiO}_{2}$ and $30 \mathrm{wt} \% \mathrm{TiO}_{2}$ anodes showed discharge capacity of 724 and $547 \mathrm{~mA} \mathrm{~h} \mathrm{~g}^{-1}$ at a C/5 rate after 100 cycles, respectively. Excellent cycling performances of the two $\mathrm{CNF}_{\mathrm{TiO}}$ electrodes may be explained as follows: (i) a suitable amount of $\mathrm{TiO}_{2}$ particles can act as active material without binder material, such as polyvinylidene fluoride (PVDF) during the lithiation/delithiation process. (ii) One-dimensional structures act as electron channels which can significantly increase the electrical conductivity. (iii) The freestanding electrode without a binder exhibits a low resistance value. (iv) Good mechanical properties of carbon nanofibers retains the structural integrity of electrodes during cycling. Further, the rate capability of the $\mathrm{CNF}_{\mathrm{TiO}}$ composite electrode (30 wt \%) was evaluated at various C-rates, as shown in Figure S3. Notably, discharge capacity of the as-prepared electrode $\left(\approx 290 \mathrm{~mA} \mathrm{~h} \mathrm{~g}^{-1}\right.$ at 3C) was much higher than that of the bare $\mathrm{TiO}_{2}$ electrode at the same conditions ( $45 \mathrm{~mA} \mathrm{~h} \mathrm{~g}^{-1}$ at $\left.3 \mathrm{C}\right)$.

(a)

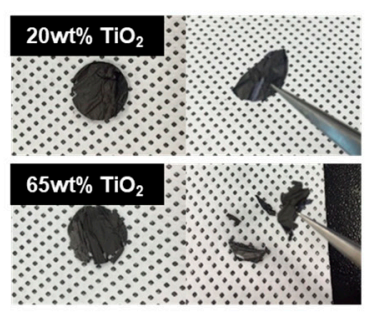

(b)

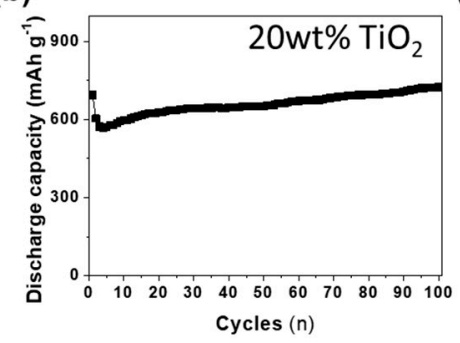

(c)

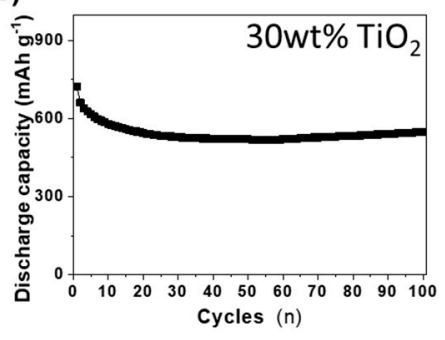

Figure 7. Electrochemical performances of $\mathrm{TiO}_{2}$ decorated carbon nanofibers electrodes with different $\mathrm{TiO}_{2}$ contents. (a) Photo images of freestanding $\mathrm{CNF}_{\mathrm{TiO}}$ electrodes. Cycle performances of (b) $20 \mathrm{wt} \% \mathrm{TiO}_{2}$ decorated carbon nanofibers electrodes and (c) $30 \mathrm{wt} \% \mathrm{TiO}_{2}$ decorated carbon nanofibers electrodes obtained at $\mathrm{C} / 2$ rate in the range of $0.01-3.0 \mathrm{~V}$.

The approach described in this study is a straightforward method for producing $\mathrm{TiO}_{2}$ on CNF. We extended this concept to decorate other metal oxides on the surface of CNF. Figure 8 shows the SEM images and the corresponding XRD patterns of CNF decorated with various metal oxides. Metal alkoxides were used as precursors for metal oxides due to their well-known protocol of sol-gel reaction. $\mathrm{Zr}$ butoxide solution was used for the preparation of $\mathrm{ZrO}_{2}$ in the same manner as Ti butoxide solution was for $\mathrm{TiO}_{2}$. As shown in Figure 8a,b, the deposition of $\mathrm{ZrO}_{2}$ nanoparticles (JCPDS file No.37-1484 and 42-1164) on the carbon nanofibers was accomplished, and their complete transformation was confirmed by indexing their representative XRD diffraction peaks. Besides, $\mathrm{SnO}_{2}$ (JCPDS file No. 41-1445) and NiO (JCPDS file No. 47-1049) decorated carbon nanofibers were successfully produced by utilizing the corresponding alkoxides (Figure 8c-f). 

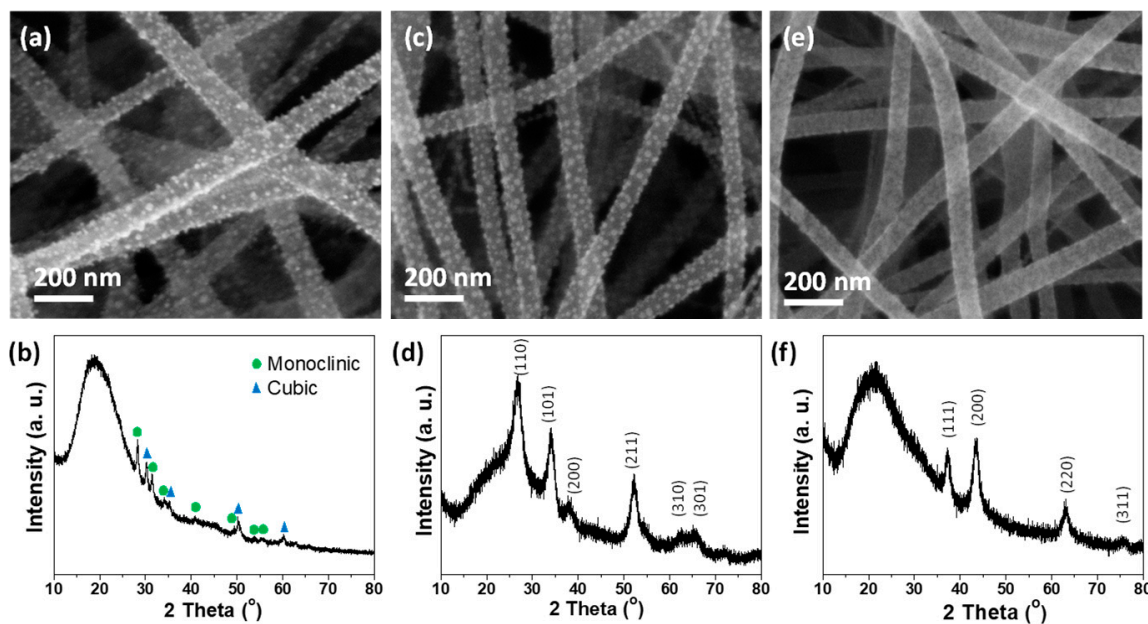

Figure 8. SEM images and corresponding XRD patterns of carbon nanofibers with different metal oxide nanoparticles: (a,b) $\mathrm{ZrO}_{2},(\mathbf{c}, \mathbf{d}) \mathrm{SnO}_{2}$, and $(\mathbf{e}, \mathbf{f}) \mathrm{NiO}$.

\section{Conclusions}

In conclusion, we have described a facile route for the fabrication of carbon nanofibers decorated with various kinds of metal oxide nanoparticles through the combination of electrospinning and sol-gel method. PAN/PVP core/shell nanofibers with the controllable diameters formed by phase-separation of two immiscible polymers, serve effectively as the supporting structures for coating with metal oxides. $\mathrm{TiO}_{2}, \mathrm{ZrO}_{2}, \mathrm{SnO}_{2}$, and $\mathrm{NiO}$ nanoparticles were successfully converted from the corresponding metal alkoxides on the surface of CNF after heat treatment. Additionally, the density of the metal oxide nanoparticles exposed to the external environment was controlled simply by adjusting their concentrations of precursor solution and could be large in quantity. Furthermore, the freestanding $\mathrm{CNF} @ \mathrm{TiO}_{2}$ electrode consisting of a nanofiber structured sheet with a good mechanical property exhibited excellent electrochemical properties, including a highly stable cycling performance (a high reversible capacity of $\approx 600 \mathrm{~mA} \mathrm{~h} \mathrm{~g}^{-1}$ at $\mathrm{C} / 5$ rate after 100 cycles) in the lithium-ion battery system. This study provides an effective route to modify the surface of CNF with metal oxides, and they are potentially applicable for use in energy-related devices, such as batteries, supercapacitors, and dye-sensitized solar cells.

Supplementary Materials: The following are available online at https:/ / www.mdpi.com/1996-107 3/14/5/1353/s1.

Author Contributions: Conceptualization, J.-P.L. and S.C. (Sinho Choi); methodology, J.-P.L. and S.C.; formal analysis, J.-P.L., S.C. (Sinho Choi) and S.C. (Sungin Cho); resource W.-J.S. and S.P., writing—original draft preparation, J.-P.L. and S.C. (Sinho Choi); writing-review and editing, W.-J.S. and S.P.; supervision, project administration, funding acquisition, S.P. All authors have read and agreed to the published version of the manuscript.

Funding: This work was supported by research fund of Chungnam National University.

Institutional Review Board Statement: Not applicable.

Informed Consent Statement: Not applicable.

Data Availability Statement: The data presented in this study are available on request from the corresponding author.

Conflicts of Interest: The authors declare no conflict of interest.

\section{References}

1. Baughman, R.H.; Zakhidov, A.A.; De Heer, W.A. Carbon nanotubes-The route toward applications. Science 2002, 297, 787-792. [CrossRef] [PubMed]

2. Avouris, P. Molecular electronics with carbon nanotubes. Acc. Chem. Res. 2002, 35, 1026-1034. [CrossRef] [PubMed] 
3. Geim, A.K.; Novoselov, K.S. The rise of graphene. Nat. Mater. 2007, 6, 183-191. [CrossRef]

4. Wang, D.W.; Li, F.; Liu, M.; Lu, G.Q.; Cheng, H.M. 3D aperiodic hierarchical porous graphitic carbon material for high-rate electrochemical capacitive energy storage. Angew. Chemie Int. Ed. 2008, 47, 373-376. [CrossRef]

5. Mauter, M.S.; Elimelech, M. Environmental applications of carbon-based nanomaterials. Environ. Sci. Technol. 2008, 42, 5843-5859. [CrossRef]

6. Jeong, S.; Lee, J.P.; Ko, M.; Kim, G.; Park, S.; Cho, J. Etched graphite with internally grown si nanowires from pores as an anode for high density Li-ion batteries. Nano Lett. 2013, 13, 3403-3407. [CrossRef]

7. Lin, Z.; Waller, G.H.; Liu, Y.; Liu, M.; Wong, C.P. Simple preparation of nanoporous few-layer nitrogen-doped graphene for use as an efficient electrocatalyst for oxygen reduction and oxygen evolution reactions. Carbon N. Y. 2013, 53, 130-136. [CrossRef]

8. Song, W.J.; Lee, S.; Song, G.; Son, H.B.; Han, D.Y.; Jeong, I.; Bang, Y.; Park, S. Recent progress in aqueous based flexible energy storage devices. Energy Storage Mater. 2020, 30, 260-286. [CrossRef]

9. Geng, H.; Peng, Y.; Qu, L.; Zhang, H.; Wu, M. Structure Design and Composition Engineering of Carbon-Based Nanomaterials for Lithium Energy Storage. Adv. Energy Mater. 2020, 10, 1903030. [CrossRef]

10. Zhang, L.; Aboagye, A.; Kelkar, A.; Lai, C.; Fong, H. A review: Carbon nanofibers from electrospun polyacrylonitrile and their applications. J. Mater. Sci. 2014, 49, 463-480. [CrossRef]

11. Feng, L.; Xie, N.; Zhong, J. Carbon nanofibers and their composites: A review of synthesizing, properties and applications. Materials 2014, 7, 3919-3945. [CrossRef]

12. Chen, L.; Feng, Y.; Liang, H.; Wu, Z.; Yu, S. Macroscopic-scale three-dimensional carbon nanofiber architectures for electrochemical energy storage devices. Adv. Energy Mater. 2017, 7, 1700826. [CrossRef]

13. Azwar, E.; Mahari, W.A.W.; Chuah, J.H.; Vo, D.-V.N.; Ma, N.L.; Lam, W.H.; Lam, S.S. Transformation of biomass into carbon nanofiber for supercapacitor application-A review. Int. J. Hydrogen Energy 2018, 43, 20811-20821. [CrossRef]

14. Li, Y.; Huang, X.; Zeng, L.; Li, R.; Tian, H.; Fu, X.; Wang, Y.; Zhong, W.-H. A review of the electrical and mechanical properties of carbon nanofiller-reinforced polymer composites. J. Mater. Sci. 2019, 54, 1036-1076. [CrossRef]

15. Hou, Z.; Li, G.; Lian, H.; Lin, J. One-dimensional luminescent materials derived from the electrospinning process: Preparation, characteristics and application. J. Mater. Chem. 2012, 22, 5254-5276. [CrossRef]

16. Fan, Z.; Yan, J.; Wei, T.; Zhi, L.; Ning, G.; Li, T.; Wei, F. Asymmetric supercapacitors based on graphene $/ \mathrm{MnO}_{2}$ and activated carbon nanofiber electrodes with high power and energy density. Adv. Funct. Mater. 2011, 21, 2366-2375. [CrossRef]

17. Wu, S.; Zhang, J.; Ladani, R.B.; Ravindran, A.R.; Mouritz, A.P.; Kinloch, A.J.; Wang, C.H. Novel electrically conductive porous PDMS/carbon nanofiber composites for deformable strain sensors and conductors. ACS Appl. Mater. Interfaces 2017, 9, 1420714215. [CrossRef]

18. Cataldi, P.; Dussoni, S.; Ceseracciu, L.; Maggiali, M.; Natale, L.; Metta, G.; Athanassiou, A.; Bayer, I.S. Carbon nanofiber versus graphene-based stretchable capacitive touch sensors for artificial electronic skin. Adv. Sci. 2018, 5, 1700587. [CrossRef] [PubMed]

19. Song, W.J.; Park, J.; Kim, D.H.; Bae, S.; Kwak, M.J.; Shin, M.; Kim, S.; Choi, S.; Jang, J.H.; Shin, T.J.; et al. Jabuticaba-Inspired Hybrid Carbon Filler/Polymer Electrode for Use in Highly Stretchable Aqueous Li-Ion Batteries. Adv. Energy Mater. 2018, 8, 1702478. [CrossRef]

20. Yanilmaz, M.; Dirican, M.; Asiri, A.M.; Zhang, X. Flexible polyaniline-carbon nanofiber supercapacitor electrodes. J. Energy Storage 2019, 24, 100766. [CrossRef]

21. Tang, H.; Chen, W.; Wang, J.; Dugger, T.; Cruz, L.; Kisailus, D. Electrocatalytic N-Doped Graphitic Nanofiber-Metal/Metal Oxide Nanoparticle Composites. Small 2018, 14, 1703459. [CrossRef]

22. Abideen, Z.U.; Kim, J.-H.; Lee, J.-H.; Kim, J.-Y.; Mirzaei, A.; Kim, H.W.; Kim, S.S. Electrospun metal oxide composite nanofibers gas sensors: A review. J. Korean Ceram. Soc. 2017, 54, 366-379. [CrossRef]

23. Dey, A. Semiconductor metal oxide gas sensors: A review. Mater. Sci. Eng. B 2018, 229, 206-217. [CrossRef]

24. Sun, Y.-F.; Liu, S.-B.; Meng, F.-L.; Liu, J.-Y.; Jin, Z.; Kong, L.-T.; Liu, J.-H. Metal oxide nanostructures and their gas sensing properties: A review. Sensors 2012, 12, 2610-2631. [CrossRef]

25. Zhi, M.; Xiang, C.; Li, J.; Li, M.; Wu, N. Nanostructured carbon-metal oxide composite electrodes for supercapacitors: A review. Nanoscale 2013, 5, 72-88. [CrossRef]

26. Konstantinou, I.K.; Albanis, T.A. $\mathrm{TiO}_{2}$-assisted photocatalytic degradation of azo dyes in aqueous solution: Kinetic and mechanistic investigations: A review. Appl. Catal. B Environ. 2004, 49, 1-14. [CrossRef]

27. Low, J.; Cheng, B.; Yu, J. Surface modification and enhanced photocatalytic $\mathrm{CO}_{2}$ reduction performance of TiO 2 : A review. Appl. Surf. Sci. 2017, 392, 658-686. [CrossRef]

28. Daghrir, R.; Drogui, P.; Robert, D. Modified $\mathrm{TiO}_{2}$ for environmental photocatalytic applications: A review. Ind. Eng. Chem. Res. 2013, 52, 3581-3599. [CrossRef]

29. Song, W.J.; Yoo, S.; Lee, J.I.; Han, J.G.; Son, Y.; Kim, S.I.; Shin, M.; Choi, S.; Jang, J.H.; Cho, J.; et al. Zinc-Reduced Mesoporous TiOx Li-Ion Battery Anodes with Exceptional Rate Capability and Cycling Stability. Chem. Asian J. 2016, 11, 3382-3388. [CrossRef]

30. Kim, C.H.; Kim, B.-H.; Yang, K.S. $\mathrm{TiO}_{2}$ nanoparticles loaded on graphene/carbon composite nanofibers by electrospinning for increased photocatalysis. Carbon N. Y. 2012, 50, 2472-2481. [CrossRef]

31. Zhang, Y.; Tang, Z.-R.; Fu, X.; Xu, Y.-J. TiO2-graphene nanocomposites for gas-phase photocatalytic degradation of volatile aromatic pollutant: $\mathrm{Is}_{\mathrm{TiO}_{2}}$-graphene truly different from other $\mathrm{TiO}_{2}$-carbon composite materials? ACS Nano 2010, 4, 7303-7314. [CrossRef] [PubMed] 
32. Li, M.; Lu, B.; Ke, Q.-F.; Guo, Y.-J.; Guo, Y.-P. Synergetic effect between adsorption and photodegradation on nanostructured $\mathrm{TiO}_{2}$ /activated carbon fiber felt porous composites for toluene removal. J. Hazard. Mater. 2017, 333, 88-98. [CrossRef]

33. Shi, J.; Zheng, J.; Wu, P.; Ji, X. Immobilization of $\mathrm{TiO}_{2}$ films on activated carbon fiber and their photocatalytic degradation properties for dye compounds with different molecular size. Catal. Commun. 2008, 9, 1846-1850. [CrossRef]

34. Ma, L.; Li, N.; Wu, G.; Song, G.; Li, X.; Han, P.; Wang, G.; Huang, Y. Interfacial enhancement of carbon fiber composites by growing $\mathrm{TiO}_{2}$ nanowires onto amine-based functionalized carbon fiber surface in supercritical water. Appl. Surf. Sci. 2018, 433, 560-567. [CrossRef]

35. Park, S.; Lee, D.H.; Russell, T.P. Self-Assembly of Block Copolymers on Flexible Substrates. Adv. Mater. 2010, $22,1882-1884$. [CrossRef]

36. Lee, J.-P.; Bang, B.M.; Choi, S.; Kim, T.; Park, S. Patterning of various silicon structures via polymer lithography and catalytic chemical etching. Nanotechnology 2011, 22, 275305. [CrossRef]

37. Park, S.; Kim, B.; Cirpan, A.; Russell, T.P. Preparation of metallic line patterns from functional block copolymers. Small 2009, 5, 1343-1348. [CrossRef]

38. Kishan, A.P.; Cosgriff-Hernandez, E.M. Recent advancements in electrospinning design for tissue engineering applications: A review. J. Biomed. Mater. Res. Part A 2017, 105, 2892-2905. [CrossRef]

39. Ahmed, F.E.; Lalia, B.S.; Hashaikeh, R. A review on electrospinning for membrane fabrication: Challenges and applications. Desalination 2015, 356, 15-30. [CrossRef]

40. Teo, W.E.; Ramakrishna, S. A review on electrospinning design and nanofibre assemblies. Nanotechnology 2006, 17, R89. [CrossRef]

41. Liu, P.; Zhu, K.; Gao, Y.; Luo, H.; Lu, L. Recent progress in the applications of vanadium-based oxides on energy storage: From low-dimensional nanomaterials synthesis to 3D micro/nano-structures and free-standing electrodes fabrication. Adv. Energy Mater. 2017, 7, 1700547. [CrossRef]

42. Asim, S.; Javed, M.S.; Hussain, S.; Rana, M.; Iram, F.; Lv, D.; Hashim, M.; Saleem, M.; Khalid, M.; Jawaria, R. RuO 2 nanorods decorated CNTs grown carbon cloth as a free standing electrode for supercapacitor and lithium ion batteries. Electrochim. Acta 2019, 326, 135009. [CrossRef]

43. Jiang, J.; Li, Y.; Liu, J.; Huang, X.; Yuan, C.; Lou, X.W. Recent advances in metal oxide-based electrode architecture design for electrochemical energy storage. Adv. Mater. 2012, 24, 5166-5180. [CrossRef] [PubMed]

44. Lu, X.; Wang, C.; Wei, Y. One-dimensional composite nanomaterials: Synthesis by electrospinning and their applications. Small 2009, 5, 2349-2370. [CrossRef]

45. Zhang, W.F.; He, Y.L.; Zhang, M.S.; Yin, Z.; Chen, Q. Raman scattering study on anatase $\mathrm{TiO}_{2}$ nanocrystals. J. Phys. D Appl. Phys. 2000, 33, 912. [CrossRef]

46. Dong, Z.; Kennedy, S.J.; Wu, Y. Electrospinning materials for energy-related applications and devices. J. Power Sources 2011, 196, 4886-4904. [CrossRef]

47. Carp, O.; Huisman, C.L.; Reller, A. Photoinduced reactivity of titanium dioxide. Prog. Solid State Chem. 2004, $32,33-177$. [CrossRef]

48. Lee, J.-P.; Choi, S.; Park, S. Preparation of silica nanospheres and porous polymer membranes with controlled morphologies via nanophase separation. Nanoscale Res. Lett. 2012, 7, 1-7. [CrossRef] 